\title{
Protection of Hydrological Heritage Sites of Serbia - Problems and Perspectives
}

\author{
Simić SavaA*, Gavrilović Bojan ${ }^{B}$, Živković NenadC, Gavrilović LjiljanaC \\ Received: April 2012 | Revised: June 2012 | Accepted: June 2012
}

\begin{abstract}
Protection of hydrological heritage sites, water protection segment, is an integral part of nature conservation. Today it is the basic theme of the hydrological heritage, the new field of hydrology and geoheritage, which, by exploring and evaluating hydrological diversity of a particular area and identifying representative water phenomena, sets their preservation and protection as one of the utmost objectives. Two main problems in the protection of water phenomena in Serbia are: inadequate attitude of the individual and society, as a result of poor knowledge of the characteristics and values of waters, and the ever-present need for men to use them (as resources). Lack of understanding, in the professional sphere, the value and importance of water phenomena in the natural system - as a result of a firmly based biocentrism in nature conservation, lack of hydrologic group within the geoheritage and a small number of interested professionals are some of the associated problems that limit the activities in this field. Specific problems - from the lack of organized and synchronized scientific research to the lack of a database on the hydrological heritage sites, are somewhat common to other segments of the nature conservation of Serbia. There are three possible directions of the future actions on the protection of hydrological heritage sites of Serbia: complete protection, protection with utilisation for the needs of tourism and protection with utilisation for the needs of water management. The most complex task of hydrological heritage will just be to combine the preservation and protection with tourism and water management, because it is diverse and often conflicting industries about. A possible solution to this problem is illustrated through the idea of water reserves.
\end{abstract}

Key words: water phenomena, hydrological heritage site, nature conservation

\section{Introduction}

Protection of water and water phenomena is an inseparable part of nature conservation. If one bears in mind the importance of water as life-giving element, it is logical to assume that the water was one of the first segments of the environment, which a man, seeing the overall value, was trying to protect and preserve. Therefore, the hydrological phenomena in the territory of Serbia were among the first sites that man, realizing their importance, was preserving and protecting. In the formal sense this is attested by the first natural monument, protected in 1949, VelikaRipaljka and Mala Ripaljka waterfalls on the Gradašnica River at the foot of Ozren Mountain near Sokobanja, hydrological heritage site today. ${ }^{1}$

\footnotetext{
1 "The hydrological heritage is part - a segment of the hydrological diversity of an area, which among the abundance of other water phenomena and sites stands out with its importance (value), which can be reflected in the environmental, resource, scientific, educational, socio-cultural and aesthetic terms" (Simić, 2009).
}

\footnotetext{
A Institute for Nature Conservation of Serbia, Dr IvanaRibara 91, Belgrade, Serbia

B The Institute of Chemistry, Technology and Metallurgy of the University in Belgrade

C University in Belgrade - Faculty of Geography, Studentski trg 3/3, Belgrade, Serbia

* Corresponding author: sava.simic@zzps.rs; 011/2093870.
} 
B. Vasiljević (1983) pointed to a widespread opinion that the protection of water and water phenomena represented solely activities to preserve and improve the natural characteristics of waters: chemical composition, physical properties, quantity and regime. In contrast, he pointed out another important aspect of their protection "which means, above all, striving to maintain and improve the condition of natural sites in which water occurs or exists (springs, parts of river beds, lakes, waterfalls)." Thought by which B. Vasiljević viewed water phenomena as a whole - as a "water mass" of certain characteristics and as a unique phenomenon in nature, that is, natural site, explains the importance of protecting water phenomena as parts of nature and emphasizes its uniqueness compared to the general protection of waters, and thus represents the main idea of the hydrological heritage.

Hydrological heritage, a new subject in hydrology - the protection of water resources ${ }^{2}$, also represents a special area within the geoheritage, which places hydrological diversityof certain area in the centre of its interest, by exploring it, evaluating and identifying extreme segments, representative water phenomena - hydrological heritage sites (Simić, et al., 2010b). Hydrological heritage site is "a manifestation of water on Earth or its specific part, where its environmental, resource, scientific, educational, socio-cultural and aesthetic values single it out from the abundance of others and make it unique" (Simić, 2009). Hydrological heritage stresses the value of its sites - as separate natural phenomena (scientific, educational and aesthetic value), integral and elementary parts of natural system (ecological value) and phenomena that are a condition of existence and development of man and society (resource and socio-cultural value), and sets their preservation and protection as one of the utmost objectives.

\section{Basic Problems of the Protection of Water Phenomena - Hydrological Heritage Sites of Serbia}

The main problems that stand out when it comes to working on the protection of water phenomena - hydrological heritage sites of Serbia are the following:

1. Inadequate attitude of individual and society towards water phenomena, which is the result of poor knowledge of their characteristics, values and importance

This is the basic and most general problem in dealing with the protection of nature and some of its seg-

2 The hydrological heritage is a subgroup in the Protection of Water Resources, which is an integral part of Water Management, complex field of Hydrology. ments, in this case, water phenomena, and is present from the very beginnings of the development of awareness of environmental protection. It would be reasonable to expect that the attitude of man towards water and its phenomena is directly related to the level of social development, that is, high environmental awareness is the characteristic of developed social systems. Unfortunately, history shows that development and progress of various segments of society do not necessarily bring an identical shift in the ecological sphere, not only because the "progress" is often based on exploitation of natural resources. Even Herodotus said for the Persians in one place: "They do not urinate in their own rivers, do not spit at them, nor wash hands in them, and do not allow any others to do so." "When we look how waters are treated today, and compare that with the above paragraph about the Persians, then it inevitably raises the question: How old Persians came to such a high understanding of the importance of water and to such a discipline in the treatment of the water?" (Turajlić, 1957).

Situation in which the society in Serbia has been for decades and inherited low level of awareness of the importance of nature conservation give an answer in advance what is the attitude of the individual and society towards water phenomena, but also all other natural sites. The most common excuse for people not interested in the protection and preservation of nature and the environment in which they live and waters as their elemental part, is that their primary concern is how to ensure economic existence, which no doubt affected a significant number of inhabitants of this country. However, if the aim is to perceive this complex problem truly, it is necessary to seriously consider the view that such socio-economic situation is certainly a consequence of exploitative attitude of man and lack of understanding of nature conservation water, and its other segments, from the past.

Intermittent springs are particularly interesting subgroup of the hydrological heritage of Serbia, within Springs ${ }^{3}$. They are characteristic for the karst terrains and their rarity and excellence as phenomena in the world are the result of a specific mode, which is reflected in the relatively frequent fluctuations in abundance and occasional breaks in flowing out. Outside the territory of the Balkan Peninsula only a few dozen of them are known. In Serbia there are three intermittent springs confirmed in science: the Homoljs-

\footnotetext{
The classification of the hydrological heritage sites of Serbia: ISprings (Springs and Karst springs, Intermittent springs, Thermo-mineral springs); IIRivers (Water resources - water reserves, Waterfalls and cascades, Lost rivers); IIILakes; IV Ponds, swamps, oxbow lakes and mires (Ponds, swamps andoxbow lakes, Mires); VHydrographic points(Gavrilović, et al., 2008; Simić,2009).
} 
ka intermittent spring in the village of Laznica near Žagubica, the Promuklica intermittent spring in the gorge of Vidrenjak near Tutin and the Bjeluška intermittent spring (Kojin spring) in the village of Bjeluša near Arilje. Several other spring in Serbia have some of the features of intermittent springs, such as: Banja in Petnička cave, the Kučevska intermittent spring, Mukavac in the valley of the Mali Rzav and others.

In science, the intermittent springs have long been known as karst phenomena, and they are even today the subject of interest and research. However, the general human ignorance often prevails over science and protection as well. An obvious example of this is the mentioned Kučevska intermittent spring, which is reliably considered to have lost its intermittent properties long ago ${ }^{4}$. Even half a century ago, D. Čolić (1953) provided the answer to the question of how it happened, and when asked why, the answer was hard to find: "In Eastern Serbia, there was only one specimen of intermittent spring, an extraordinary example of the karst hydrography, which is not only important for science and education, but by its siphon process at regular intervals represents an attractive and interesting tourist attraction. Today this site is gone, and who wants to see how the intermittent springs work, the closest that he can find them is in the Lika karst. - In order to get some stone to build a nearby road, the intermittent spring is broken and shattered, and the stone pounded. So a road, rather than to contribute to greater tourist importance and exploitation of a beautiful natural object by making it more accessible to tourists and visitors, on the contrary wiped it from the earth."

\section{Are there real solutions?}

As utopian as it may sound, the only way lies in clear plan and direction of the state that this segment of the social activity and science - conservation of nature and geodiversity, and thus the protection of water and the water phenomena - hydrological heritage, is properly arranged, both theoretically and systemically (law), and one of the most important segments of such social action would be the introduction of nature conservation into the education system. Nature conservation should be introduced as a compulsory subject in elementary and partly secondary schools. When it comes to higher education, according to specialization, environmental protection should also exist as a basic subject, which, depending on the discipline or faculty, could be transformed into a narrower specialization - biodiversity conservation for biologists and ecologists and the protection of geodiversity

4 Thanks to the fact that it used to represent a school example of the unique hydrological phenomenon - intermittent spring, this spring has today been a hydrological heritage site of Serbia in the procedure of the protection. (geoheritage) for geologists, geographers, pedologists and archaeologists.

Regular, organized work on the development of ecological culture of the common man is also required, particularly in rural areas, where there are best preserved and most valuable natural resources, including hydrological heritage sites. It should be insisted on building the proper relationship not only to water and its phenomena, but to the entire natural environment, to provide real answers to the question of what a person receives by such ("regular") relationship with nature and to systematically bring the nature conservation closer to people. In this way, protection would not be experienced only as a kind of ban and restriction on freedom of action in space, but ideas and concrete actions would be initiated by which, thanks to preserved nature and biodiversity and geodiversity, quality of life would be improved.

\section{Permanent human need for the use of water phe- nomena asresources}

Water is the most important matter on Earth, and its exceptional phenomena - hydrological heritage sites are, due to their ecological, scientific, educational, socio-cultural and aesthetic values, valuable resource for man and society, and become more and more vulnerable with the permanent increasing of the needs (Simić, et al., 2010b).

One of the common values, and also the basic functions of water is that it is a resource that needs to meet the needs of man and society for a certain amounts especially drinking water, and then the water for other social activities. However, the society passed a reasonable level of exploitation of (drinking) water resources long ago and the water crisis in the world has already been present, and the prospect is not optimistic.

"At a time when there are more and more conflicts between tendencies directed towards protection and utilitarian activities opposed to them" (Đurđić, Filipović, 2005), raises the issue of harmonization of relations between water as a resource and water (water phenomena) as a natural value.

The specific issue that well illustrates the relationship of real human needs for water, on the one hand and protection of unique natural values of some water phenomenon, on the other hand, is not whether karst spring should be protected as a hydrological heritage site and thus saved from exploitation, but whether the capture of springs is long-term and optimal solution to the problem of water supply of an area or a temporary (or insufficiently tested solution), which can produce two bad consequences: it will not resolve (due to poor projection) the question of basic water needs of a given area, and at the same time it will degrade hydrological heritage site. 
It is an undeniable fact that the capture of strong karst springs, especially those the (height) position and distance of which are favourable in relation to the users, is usually a high-quality and cost-effective solution of the water supply issues of specific area.

Regional Water Supply of the City of Niš is based on the capture of a large number of karst springs and their linking into a single system. It includes some of the strongest springs of Eastern Serbia: the Lužnička springs near Babušnica, springs in the vicinity of BelaPalanka and the Krupačko spring in the valley of the Nišava. The Lužnička springs with the canyon are valued as a natural monument, and the Krupačko spring, which represents a hydrological heritage site of Serbia, is protected as a natural monument. The protection of this site meant compromise with the need to use this resource, and it was agreed to carry out the water intake with the least possible change of the natural look of the spring, and the investor accepted the obligation to arrange environment. However, the strict measures of sanitary protection and the knowledge that the spring in dry period remains without artery, confirm the view that this hydrological heritage site has suffered considerable changes, which are reflected primarily in the hydrological regime disorder (Vasiljević, 1983). Also, limited access and visits, given that it is about a monument of nature in the protection regime of the II level, greatly degrade the values and characteristics that make this spring protected. This is yet another example that the main approach to the problem of water supply is still based on a unilateral focus on the exploitation of water - springs, as natural resource, which does not and cannot have different purpose and value.

Waterfalls and cascades are a special subgroup of the hydrological heritage of Serbia, within Rivers. However, we should not forget that most waterfalls are classified into geomorphologic phenomena. Thus S. Stanković (2004) also includes them into "geomorphologic sites of the geoheritage of Serbia, which are often combined with hydrological and bio-geographical ones." Morphological dependence of these exceptional natural sites is obvious, but the water is their dominant element, without which they would be "just interesting sections or steps in the river bed" (Simić, et al., 2010b). Hence it is proper and logical that within the geoheritage of Serbia the waterfalls can be found in the lists of both geomorphologic and hydrological heritage.

On what happens when human ignorance and "the need for the use of resources" agree says another example of the record of D. Čolić (1953), which is unfortunately current even today. He only testified in favour of a close link - inseparability of the problem in the protection of water phenomena: “... we talked about VelikaRipaljka waterfall near SokoBanja. Today, this popular resort is in such a state that it serves not as a natural beauty, but as an eyesore of this part. Finding that SokoBanja does not well supply with electricity the sanatorium under Ozren, and since it has not been connected with transmission line that supplies electricity to a nearby mine, the local labour union of the sanatorium came to the original idea. On own initiative, without asking authoritative review and approval from anyone, it organized volunteer work, partitioned and sealed up the waterfall by some monstrous drain that resembles shuttles on a Grill and brought water to an impromptu shed in which it placed a small turbine and generator. The gain of a few kilowatts is negligible and the situation in this regard is not particularly improved. Today the entire area is regularly supplied with electricity, but this eyesore is still there, and VelikaRipaljka is gone. And whoever wishes to visit this place known to him by reputation, he will not be able to see the most beautiful waterfall of Serbia, but something that resembles not even a village mill."

Unfortunately, even today, almost 60 years after this record, it can be argued that the relationship of man to water phenomena in this area has changed greatly. Ripaljka waterfall, the first site in Serbia that is protected as a natural monument, is still largely without water.

The use of clean drinking water can often be in disagreement with its protection - as a hydrological heritage. Current Law on theNature Conservation("Official Register of the Republic of Serbia", no. 36/09, 88/10 and 91/10), within the Special Nature Reserve also identifies hydrological reserves, which in hydrological heritage should be an example that will prove that it is possible to "reconcile" the two opposing activities.

Water resources - water reserves (parts of river basins), 33 of them, taken out of the Law on utilization and protection of water supply sources ("Official Register of the Republic of Serbia", no. 27/77, 24/85 and 29/88) were already classified in hydrological heritage sites of Serbia, within the second group - Rivers (Gavrilović, et al., 2008). The problem is that they are not clearly defined spatially and therefore it is difficult to harmonize them as such with the system of protection. The idea of water reserves as natural resources of precisely defined boundaries involves the identification of parts of space which is characterized by the richness, diversity and the high value of hydrological phenomena. They certainly would not be associated with the mentioned sources from the list, but they can be formed also in other areas of Serbia, which meet the relevant criteria. Creation of hydrological - water reserves, special and new types of protected natural resources, is the need, which will have as a final goal the fundamental protection of water as basic and unique values, but also protection of the entire complex of the 
natural environment of an area (Simić, 2011). The use of water resources in the future could potentially be one of the main functions of these resources, but only with the highest level of conservation of hydro-geographical and all other natural values.

\section{Lack of understanding of the value of water phe- nomena and their importance in the natural sys- tem - hence the inadequate evaluation}

This issue primarily involves the relationship of experts towards the protection of sites of "inanimate nature" - the geoheritage. Although the protection of nature as an area of social activities and professional (scientific) disciplines has long been present, it is still usually related to the protection of wildlife - biodiversity. That was the main reason that a number of specialists in various fields of Earth sciences launched the idea of geodiversity and geoheritage, initially as a response or counter to biodiversity. Noticing the analogy between biological diversity and diversity of non-living world and introducing the concept of geodiversity, they tried by re-emphasizing the unity of the two indivisible components of nature - "animate" and "inanimate" to direct traditionally rooted biocentrist approach in the nature conservation to the holistic one, which is the only proper and complete according to them (Simić, et al., 2010a). Therefore, it should not be surprising that one of the creators of this concept and idea, C. Sharples (2002), almost poetically calls the geo-conservation - protection of geodiversity and its shapes and forms "the forgotten half of the nature conservation."

On the low level of understanding of the value and importance of hydrological heritage sites clearly speaks the analysis of their condition in the system of nature protection in Serbia. Except the water phenomena, which exceptional values in science and in society have previously been known and recognized, as Intermittent springs and Waterfalls and cascades, other groups - Springs and Karst springs and Thermo-mineral springs have no considerable level of protection, while the Lost rivers (Underground streams) and $\mathrm{Hy}$ drographic points so far practically have never existed in nature conservation. Good status in the protection of Lakes, that is, Ponds, swamps, oxbow lakes and mires, hydrological heritage sites (groups), which are characterized by complex - environmental, scientific, aesthetic and other values, does not provide a realistic picture, since these sites are not valued and protected due to their hydrographic characteristics - they are not regarded as hydrological heritage sites. Their protection is based solely on ecological values, in terms of importance for biodiversity, because they are extremely valuable and rare habitats of flora and fauna (Simić, 2009).

Hydrological heritage, the segment of geodiversity and geoheritage, which is perhaps the strongest and deepest of all connected with the living world, wants to point to the unequal treatment of two basic parts of geographic shell - a "living" and "inanimate", but not to separate its phenomena and sites from the first one.

"As geodiversity occurs or represents the richness and diversity of the four building components of the geographic shell, so the diversity of each of them stems from their interaction, overlap and unity. Hydrological heritage, thus speaking, did not occur in isolation - the abundance of the hydrosphere, but it is usually just a product of joint action and pervading of all spheres of geographic shell. Let us take an example of tufa cascades and accumulations in the foot of karst springs, which seem to fully support the previous assertions" (Simić, et al., 2010a).

Through the study of hydrological phenomena, their richness and diversity and through their evaluation as unique phenomena in nature, hydrological heritage has the task and aim to emphasize in reasoned and scientifically based manner the importance of their preservation and protection, emphasizing their independent value as parts of nature, which form a unique whole with the living world.

\section{Lack of hydrological group of sites within the geo- heritage of Serbia}

The National Council for Geoheritage of Serbia and the existing working groups have been recognized subjects that participate in the protection of geoheritage sites and have a major role in proposing concrete sites for protection and their promotion.

The National Council for Geoheritage of Serbia of 11 members -5 geologists, 4 geomorphologists, one archaeologist and one pedologist was founded in 1995. It consisted of 16 working groups, which first tasks were: preparing a list of the geoheritage sites in the field of a particular work group and creating a list, based on the previous, of particularly significant sites. Among them there was no group for hydrology - hydrological heritage. Thus, water phenomena were not taken into consideration as a unique and separate entity, so some of them were found in the geomorphologic and hydrological groups of sites, as is the case with the Inventory of Serbian Geoheritage Sites (2005).

This is somewhat understandable given the contemporary development of the idea of geodiversity and geoheritage. Since the pioneers of this idea were mainly geologists, their interest in this area was related to specialized fields - the various disciplines of geology. This led to the identification of geodiversity and geoheritage with geological diversity and geological heritage, and the existing definitions of these terms did not include an entire sphere of geographic shell hydrosphere, with its variety, shapes and phenomenahydrological heritage sites. 
Geodiversity, as a variety of geographic shell (environment) which is a result of geological, geographical and anthropogenic impacts (Lješević, 2002/2003), is now in the professional world observed and studied in the whole, with the hydrological diversity and hydrological heritage, its integral part. Therefore it is also necessary to officially introduce the Working Group on Hydrology into the National Council for Geoheritage of Serbia. A good circumstance is that the group practically already exists and operates, as evidenced by a significant number of papers on hydrological heritage of Serbia, as well as the existing preliminary list of sites - a total of 272 sites (Simić, 2009). The main task of this group would be in cooperation with the Institute for Nature Conservation of Serbia and other scientific and professional institutions to coordinate the work on establishing a system of hydrological heritage, with the goal of full inclusion of hydrological heritage sites in the system of nature conservation and the further expansion and improvement of this idea. The problem of non-existence of hydrological group within the geoheritage of Serbia is to a considerable extent the result of the following problem.

\section{A small number of experts dealing with the hydro- logical heritage}

It is obvious that biocentrism in nature conservation would not be so ingrained that there was a sufficient number of experts from Earth sciences who would also deal with the segment of the research, evaluation and protection of geodiversity. As it was not expected that the biologists were involved in geodiversity, so one should not criticize geologists, the catalysts of fresh idea on geodiversity, why they did not deal with hydrological heritage.

Serious task of hydrological heritage should also be the organization and implementation of concrete activities to involve a larger number of hydro-geographers, physical geographers and other professionals interested in working in this field. Given that hydrological heritage is a new and unfamiliar branch of hydrology and geoheritage, there are great opportunities for research. Hiring a larger number of experts, the hydrological heritage would obtain the necessary impulse for further development and promotion of idea, which would provide a better perspective of the status of its sites in the geoheritage, but also in the system of nature protection.

The impression is that the fundamental problems in the protection of hydrological heritage sites of Serbia are strongly intertwined, interrelated and as such complex to be resolved. On the other hand, improvement or resolution of one of them could lead to progress or possibility of improving some of others - and these are all steps toward overall improvement of the situation in the protection.

\section{Specific Problems of Protection of Water Phenomena - Hydrological Heritage Sites of Serbia}

Besides these basic problems in the work on water protection and its phenomena, there are a series of individual, also significant problems, which are primarily related to the work of official institutions:

\section{The absence of organized and synchronized scien- tific research}

Institute for Nature Conservation of Serbia ${ }^{5}$ should be, as a major state institution which main subject is research, evaluation and placement under law protection of the parts of space which are characterized by outstanding natural features, a carrier of activities that involve organized and synchronized scientific research in nature conservation. This approach, which is very poorly represented in the work of this institution, is necessary in nature conservation, including hydrological heritage sites, because any conservation must be established and based on scientific research. This is a consequence of almost complete lack of cooperation with scientific and educational institutions, without which it is impossible to carry out these activities. Specifically, the work in the field of hydrological heritage must be part of the institutions, such as: Faculty of Geography, University of Belgrade, Department of Geography, Tourism and Hotel Management of the Faculty of Natural Sciences in Novi Sad, the Geographical Institute "Jovan Cvijić" SASA, Department of Geography of the Faculty of Natural Sciences in Niš and Faculty of Mining and Geology in Belgrade. It should also include the "people on the ground" who are a valuable source of information and data, which can be of great importance in organizing and implementing the whole work in this area.

\section{Lack of presence of the competent institutions in the field}

Here is primarily meant on the lack of quality control in the natural resources and other valuable natural parts of Serbia, which is also one of the main tasks of the Institute for Nature Conservation. This results in very poor condition of the protection of already few

\footnotetext{
Headquarters of the Institute for Nature Conservation of Serbia is in Belgrade, and it also comprises the working unit in Niš and the Priština working unit. The Working Unit in Novi Sad developed into the Provincial institute for Nature Conservation in 2010.
} 
protected hydrological and most other natural sites. For this reason, the protection mostly remains formal - just a "dead letter". Many of the hydrological sites are severely endangered or even lost those natural features which made them valuable and conserved; many natural resources no one has visited for decades, many of them no longer exist. So today we have natural resources such as waterfalls without water(„water"fall Ripaljka), drained lakes, ponds, swamps, oxbow lakes (mass transformation in agriculture area), sources destroyed by capturing and draining, mires damaged by exploitation orurbanization (Peštersko polje, Vlasina, Divčibare)and the like.

\section{Each hydrological heritage site, which meets the} criteria by which it could be independent natural resource, must be managed as a separate site, even if it is located within a larger natural resource

Observing the Preliminary List of the Hydrological Heritage Sites of Serbia (Gavrilović, et al., 2008, Simić, 2009), it is clear that they are chosen in such a way that practically can be natural resources for themselves. Disregarding whether it is the resources about, which are dotted areas, water reserves and lakes, which are larger areas, or Lost rivers (Underground streams), which are line sites, they are usually clearly individualized, of independent natural values. The greatest number of them is of small dimensions, so that most among them are natural monuments.

In the past two decades a practice has been introduced and formalized in the nature conservation when smaller natural resources that are found within larger ones become their integral part and are no longer listed as independent natural resources in the archives (and database). In morphometric terms - such phenomena are generally just registered, they are only in passing mentioned in the protection studies, and not particularly marked in the field. This practice has led to the many valuable phenomena, geoheritage and hydrological sites, be "lost and drowned" in the major natural resources, especially if they have not been introduced as separate sites in the system of protection. Somewhat better is the state of monuments of nature and a few reserves which had the "old" protection.

It is essential that all natural sites, in this case water phenomena - hydrological heritage sites, which are distinguished by such natural values that could be monuments of nature, water reserves or other types of protected areas, are separately marked and in some way autonomous within the larger natural resourceThus, the specific values of larger natural resource would be properly highlighted, and these individual sites better promoted, and thus more popular and accessible(Like Degurićcave-karst spring and Gradac karst spring, within Landscape of outstanding features "Gradac river gorge").There is an obvious practical side of this model of protection, because, among other things, possible cases could be avoided as if a major natural resource loses its values due to which it is protected, it automatically will lead to a loss of protection of all other proclaimed or non-proclaimed natural resources within its terms, even if they preserved their natural values.

For such "resources in the resource" special elaborates on the protection would not be made, but within the studies of the major natural resource they would have an adequate space, where their natural values, location, and other scientific importance would be fully presented. In the field, they would be specially marked and thus kept and protected in the archives (Simić, 2009).

According to S. Belij (2008), the state of protected geoheritage sites of Serbia is not satisfactory one. Monuments of nature that are located within the major natural resources are not labeled, so they are unknown to majority of people. Those protected 20, 30 or more years ago, with rare exceptions, have been neglected and largely unsupervised. When it comes to the management, supervision and labeling - the general state of the natural resource, the situation is only slightly better with monuments of nature - geoheritage sites, which are preserved in the last decade.

\section{Lack of database on hydrological heritage sites (non-uniformity of data)}

So far there was no unified database of hydrological heritage sites. Within a database of protected natural resources, data on protected hydrological phenomena can be singled out, but only those that are natural resources for themselves. The problem of non-uniformity of data is also present.

The unique database that combines the existing one on the protected natural resources with the newly one - hydrological heritage sites of Serbia can be a good basis for further activities in this area (Simić, 2009).

The future protection of hydrological phenomena should be conducted in cooperation with the Working Group for Hydrological Heritage of the National Council for Geoheritage of Serbia. A unique list of sites must be created, as well as priority sites for protection and it should be insisted that, if possible, the name of each site in the list is the name of the future protected resource. This would also facilitate the work of establishing a system of hydrological heritage of Serbia.

These specific problems due to their cause, unfortunately, are not limited to the protection of water phenomena, but are significantly present in other segments of environmental protection in Serbia. 


\section{The Perspective of Protection of Water Phenomena - Hydrological Heritage Sites of Serbia}

Problems in the protection of water phenomena in Serbia are numerous, so the question is what the perspective is.

As a guideline some thoughts of D. Čolić (1953) can be used who, dealing with the essence of the concept of natural rarity in nature conservation that is represented by the geoheritage site in the geodiversity, emphasized its twofold character: as a site of scientific research - "because of which it cannot be allowed to be destroyed," and as tourist facility - "because of which it must be kept and maintained in its original natural state."

Circling this great observation of D. Čolić, a pioneer in environmental protection in Serbia, which is also applicable to the water phenomena, we have concluded that there are three real directions in which activities on the protection of any individual hydrological heritage site can move:

\section{Complete protection}

It refers to extremely valuable and unique hydrological heritage sites which should be fully preserved in their current condition. Protection regime that would be implemented on them would be of the first degree, which includes strict protection with the possibility of scientific researches and controlled visit for "educational, recreational and cultural purposes." ${ }^{\text {A }} \mathrm{A}$ small number of these sites is identified and clearly defined in space and they would be protected in the classical way - most often as natural monuments. However, it is expected that most of the potential sites of this group is an integral part of the intact or preserved parts of Serbia, of high and complex natural values, some of which already enjoy some forms of protection. The protection of such hydrological heritage sites would be organized as part of strictly protected areas - different types of strict and special reserves, parks of nature, national parks, geoparks and other major natural resources. It should be noted that in the selection of such most valuable hydrological phenomena, an issue of universal criterion is of crucial importance,

According to the Law on the nature conservation of Serbia (Official Register of the Republic of Serbia, no. 36/09, 88/10 and 91/10), geoheritage is not included into the first degree protection regime. It unjustifiably refers exclusively to the living world: "The protection regime of the first degree - strict protection, is carried out on the protected area or its part with the original or slightly changed ecosystems of extraordinary scientific or practical significance, by which the processes of natural succession are enabled and preservation of habitats and communities in the conditions of wilderness." which still represents one of the outstanding issues of the entire geoheritage.

Concrete examples of Hydrological Heritage Sites that deserve complete protection/conservation should be looked for among: Intermittent springs-the Homoljska intermittentspring, the Bjeluška intermittent spring; Waterfalls and cascades - waterfall under the DonjeBukoravačko lake; waterfall Prskalo,Sopotnica cascades, Staraplaninawaterfalls (Piljski, Čunguljski); Lost rivers (Underground streams) -Lazar's RiverDemizlok;glacial's lakes of Šarplanina and Prokletije (GornjeBukoravačko lake, Defska lakes, Jažinačka lakes, Livadičko lake, Šutmanska lakes, Đeravička lakes, Travno lake, Crno lake); mires: Veliki beg, Tihavoda (Šarplanina), mires on the edge of the Dajićko and Košaninovolakes (mountain Golija), Crvenipotokon mountain Tara...

\section{Protection with utilisation for the needs of tourism}

The objective and perspective of protection of hydrological phenomena - hydrological heritage sites cannot be just in their conservation - an absolute protection. If the natural value of a site justifies its protection, in the sense that it is not used as water resource, we cannot and should not defend its importance as an interesting phenomenon in nature. This opens a new aspect to one of the objectives of the idea of geoheritage that, except the preservation, protection and presentation of sites of inanimate nature, wants to bring them closer to man, thus affirm them, and if it is possible to realize the profit. It is of course on tourism. Tourism, as one of the objectives of idea of geoheritage, is also one of the perspectives of hydrological heritage of Serbia. Although in hydrology it is often seen in the water management, tourism is a particular form of exploitation and utilisation of water sites as resources for the needs of man. The man here, as usual, appears as a user, but not the user - simple exploiter of their natural values, but the user - tourist, who visits them, observes, investigates, meets and enjoys them.

D. Jovičić and J. Brankov (2009) in the functional classification of tourist attractions - the basic factor which primarily causes the development of tourism in a particular area, identified hydrological sites as separate species. Hydrological heritage sites are divided according to the prevailing value they possess, so they may be the subject of interest to different groups of people: scientists, experts and students if the scientific value is dominant, children and students when it comes to the educational value, "ordinary people" if aesthetic values are expressive. Even if they are not a central part of a tourist offer, geoheritage and hydrological heritage sites can be very interesting parts of larger tours. Through the idea of geoparks, which represent areas with exceptional wealth of geodiversity, 
an attempt was made primarily to highlight the importance of geodiversity sites both in science and nature protection, but also to set them at the centre of some aspects of tourist trends. Water reserves, which would unite representative hydrological heritage sites in certain areas, in perspective could be very interesting for some complementary aspects of tourism, from the scientific and educational to adventurous and extreme (Simić, 2009).

The best examples that could illustrate idea of integrating conservation and tourism could be found among Lakes - the Hydrological Heritage Sites that are characterized by the most complex values: Belocrkvanskalakes, Vlasinskolake, Palićkolake, but also among Ponds, swamps andoxbow lakes, that are attractive to tourists for a very long period of time: Bukinskirit, Zasavica, Obedskabara, Monoštorski rit.

\section{Protection with utilisation for the needs of water management - water supply, irrigation, hydraulic engineering, navigation and fish farming}

This segment in the protection of waters and hydrological heritage is the most complex because it also represents an ever-present problem and the inevitable trend of development. It needs to answer the question: How to preserve and protect, and again - in both quantitative and qualitative terms, provide water for nature and society, the most important substance on Earth?

It is obvious that water is both as a resource and in the theoretical and practical terms an integral part of the hydrological heritage and with the preservation and protection it makes a closed circle - the first cannot and will not be without the latter, and vice versa. For only when some water phenomenon becomes a resource only, without any idea and activity in order to preserve its complex (natural) values, one can broadly say that it ceases to be a hydrological heritage.

Inevitably, many of the hydrological heritage sites partially or completely lose their natural values as they become a natural resource. Taking into account this fact, one of the main tasks of the hydrological heritage is to create preconditions for optimal preservation and protection of its sites and water in general through activities primarily on forecasting and planning. We should not forget that the preservation and protection of water phenomena - hydrological heritage sites as independently valuable parts of nature and the basic components of natural system, are absolutely important.

If for a moment we go back to the idea of water reserves, as identified and protected areas of outstanding natural and hydro-geographical values, then it seems that in their frameworks it is practically possible in the functional and any other sense to adjust the zones of complete (absolute) protection, zones established for certain forms of tourism and zones that will mostly be used for water management purposes ${ }^{7}$.

The Gradac gorge, cut into the centre of the Valjevo Mountains, near the town of Valjevo, today protected "only" as a Landscape of outstanding features, could be one of the first such areas in Serbia. The wealth ofhigh quality waters - rivers, which have almost the entire length of the Gradac in class I and springs (karst) - Gradac(partially captured for water supplies of Valjevo)and Degurić springs are hydrological heritage sites of Serbia, is completed by a variety of other segments of geodiversity - the presence of geomorphologic and speleological heritage sites, which, together with significant biological diversity (in ichthyologic, ornithological, herpetological and botanical sense) is a unique natural whole, ideal for this kind of complex and functional protection.

\section{Conclusion}

Problems in the protection of water phenomena and sites in Serbia result from wrong theoretical assumptions in the approach to this subject (hydrological heritage has recently been present and recognized in the geoheritage), and reach the specific activities that are not adequate. Many of these problems are common, typical for the protection of nature and not confined to certain groups of natural sites, such as hydrological in this case or for certain segments of the environment. Such problems are improper attitude of man towards the natural environment and its phenomena, or a continued need of man for the use of nature as a resource, and water is in the centre. However, there are problems related to hydrological heritage and protection of water phenomena in the professional sphere, such as insufficient understanding of the value and importance of water phenomena in the natural system. Among other things, this is the consequence of insufficient number of researchers who deal with this issue and the lack of real institutional support (Working Group for Hydrological Heritage has still not been officially recognized as part of the National Council for the Geoheritage of Serbia).

Other problems are more related to the work of relevant institutions, notably the Institute for Nature Conservation of Serbia, that give insufficient attention to topic such as hydrological heritage. This is the consequence of significant deficiencies in the work of this institution: the absence of organized scientific research, which is the foundation of every protection,

\footnotetext{
Mentioned zones would include individual water phenomenahydrological heritage sites, but also other natural sites or entities of both 'animate' and 'inanimate' world.
} 
and lack of professional supervision in the natural resources and other valuable natural parts of Serbia. The result is an extremely poor state of protection of few protected hydrological and most other natural sites.

What is noticeable, and in no way encouraging is that the specific problems in this area of the nature conservation are the same, and perhaps more serious than in the 196os. This is evidenced by examples of irrational exploitation, degradation and destruction of representative water phenomena in Serbia in the middle of the last century, which have been current in the same places today.

Protection of water phenomena in Serbia is restricted by serious problems and deficiencies in the work, but on the other hand the way by which it should develop is obvious. It is therefore of great importance that this particular segment of nature conservation and geodiversity has now been one of the main issues and tasks of the newly formed field of hydrology and geoheritage - hydrological heritage. Current and future directions in the protection, preservation and distribution of water phenomena in Serbia are: complete protection, tourism and the use for the water management purposes. It is the alignment of these seemingly rather conflicting than complementary activities (functions) that would be one of the major and most serious tasks of hydrological heritage.

Hydrological heritage and protection of water phenomena cannot and must not only be the subject of interest of the individual, profession or science. It is necessary that the entire social system in Serbia shows interest and commitment to be a carrier of these activities through the institutions. If this does not happen, then it is illusory to talk about any future work on its hydrological heritage.

\section{References}

Belij, S. 2008. Status and Protection of the Geodiversity and Geoheritage Sites in Serbia. Protection of nature 6o/1-2, 349-358. (in Serbian)

Čolić, D.1953. Natural Rarities and their Importance to Tourism. Protection of nature, 4-5,321-354. (in Serbian)

Đurđić, S., Filipović, D. 2005. A Treatment of Protected Natural Assets in the System of Spatial Plans.
Bulletin of the Serbian Geographical Society 85, 1, 241-248. (in Serbian)

Gavrilović, Lj., Belij, S., Simić, S. 2008. Hydrological Heritage of Serbia - the Preliminary List.Protection of nature 6o, 1-2, 387-396. (in Serbian)

Jovičić, D., Brankov, J. 2009. Tourism Attractions Key Elements of Tourism Resource Base. Bulletin of the Serbian Geographical Society 89, 1, 3-12.

Lješević, M.A. 2002/2003. Geodiversity as a Condition and Expression of the Environment. Collection of papers, Faculty of Geography 50, 17-32. (in Serbian)

Sharples, C. 2002. Concepts and principles of geoconservation. Hobart: Tasmanian parks \& Wildlife service.

Simić, S. 2009. Hydrological Heritage in the System of Nature Protection in Serbia. Master thesis, Belgrade: Faculty of Geography. (in Serbian)

Simić, S., Gavrilović Lj., Belij, S. 2010b. Hydrological Heritage - a New Direction in Hydrology and Geoheritage. Bulletin of the Serbian Geographical Society 90, 4, 83-102.

Simić, S., Gavrilović, Lj., Đurović, P. 2010a. Geodiversity and Geoheritage - a New Approach to the Interpretation of Terms. Bulletin of the Serbian Geographical Society 90, 2, 1-8.

Simić, S. 2011. Hydrological heritage within protection of geodiversity in Serbia - legislation history. Journal of Geographical Institute "Jovan Cvijić" SASA 61, 3, 17-32.

Stanković, S. 2004. Touristic Valorization of Geomorphological Objects of Geo-heritage in Serbia. Bulletin of the Serbian Geographical Society 84, 1, 79-88. (in Serbian)

The Inventory of Serbian Geoheritage Sites. 2005. Belgrade: Institute for Nature Conservation of Serbia.

The Law on theNature Conservation. Official Gazette of the Republic of Serbia, No 36/o9, 88/10, 91/10. (in Serbian)

The Law on utilization and protection of water supply sources. Official Gazette of the Republic of Serbia, No 27/77, 24/85, 29/88. (in Serbian)

Turajlić, S. 1957. Water Protection in PR Serbia. Protection of nature 10, 1-9. (in Serbian)

Vasiljević, B. 1983. Special values of hydrological phenomena and issues on their protection in SR Serbia. Protection of nature 36, 11-126. (in Serbian) 